\title{
Does specialist respiratory education make a difference to practice?
}

\author{
Carol Kelly* \\ Faculty of Health, St. Helens Road, Ormskirk, Lancashire, L39 4QP, United Kingdom
}

\section{A R T I C L E I N F O}

Article history:

Accepted 7 February 2010

Available online $\mathrm{xxxx}$

\section{Keywords:}

CPD (Continuing Professional Development) COPD (Chronic Obstructive Pulmonary

Disease)

Education

Practice

\begin{abstract}
S U M M A R Y
Introduction: Chronic obstructive pulmonary disease (COPD) poses a huge burden to society. Continued professional development can be regarded as a requisite for implementing quality care. Within the literature the effectiveness of COPD care is evident, yet it is seldom attributed to the educational attainment of healthcare professionals. This study aimed to examine whether a nationally delivered COPD module is perceived to impact on clinical practice.

Methods: As part of a mixed methods study (Cresswell et al., 2003), qualitative data were gathered postintervention from 68 students utilising a semi-structured, self-completed questionnaire. Data were analysed using a themed content analysis and a quasi-statistical approach.

Results: The major themes that emerged from the analysis were: changes in personal practice, evidence of changes implemented and changes in participants' personal views regarding disease management. These findings suggest that when students gain knowledge they use it to the benefit of patients.

Discussion: Overall students reported an increase in knowledge and confidence regarding COPD management and an impact on practice was reported. The findings will add to a mounting body of evidence that supports the value of continuing professional learning and will aim to satisfy consumers of education of the efficacy of knowledge in terms of direct patient impact.
\end{abstract}

(c) 2010 Elsevier Ltd. All rights reserved.

\section{Introduction}

Continuing Professional Development (CPD) can be undertaken as a requirement for continuing professional registration, as part of a pathway to enhance academic qualifications or to enable development of clinical services. There is however historically a lack of research supporting the efficacy of CPD on clinical practice (Hogston, 1995; Ellis, 1996; Wildman et al., 1999); no doubt a potential contributing factor towards the current state of poorly funded and inequitable provision of post-registration education. Additionally, demands on both personal and professional time are great and often within constraints of limited resources. These factors often mean the need for specialist knowledge in order to improve clinical services is often not seen as a priority, for either recipients or purchasers of education, and is often the case with respiratory education (Upton et al., 2007; Fletcher, 2007). Ultimately consequences of this lack of specialist education have been shown to result in delivery of sub-optimal care to respiratory patients (Upton et al., 2007).

\section{Background}

Chronic obstructive pulmonary disease (COPD), a progressive and disabling long term condition, is a major cause of mortality

\footnotetext{
* Tel.: +44 01925 753774; fax: +440151529 3943.

E-mail address: carol.kelly@respiratoryeduk.com
}

and morbidity worldwide (Global Initiative for Chronic Obstructive Lung Disease (GOLD), 2009).

In the United Kingdom (UK) prevalence of COPD is known to be of significance with 0.6 million people diagnosed, but estimates suggest that another 7-8 million people could have the disease (British Lung Foundation (BLF), 2007). This deficit between predicted and known cases of COPD is often attributed to the poor skills, knowledge and training of health care practitioners involved in diagnosing COPD correctly (Upton et al., 2007; Fletcher, 2007) and can be seen as a contributing factor to the 'missing millions' (BLF, 2007).

In the UK this diagnosis is often established in primary care and can be the remit of both nurse practitioners and physicians. Driven by national directives such as the Quality Outcomes Framework (QOF) of the General Medical Services Contract (British Medical Association, 2003) and a health care agenda that is promoting a primary care led National Health Service (NHS) (Department of Health, 2006), the onus on healthcare professionals to meet given targets for correct diagnosis of COPD is amplified. Juxtapose to this is a seemingly lack of acknowledged competencies and standards necessary for healthcare practitioners with regards to establishing a safe and accurate diagnosis. Anecdotal evidence suggests that the identification of training needs, and the educational input necessary to address these needs, is often left to the discretion of individuals or primary care organisations.

Following diagnosis patients also have complex needs, including management of physiological, palliative and psychosocial 
consequences, including the impact on families and carers (Guthrie et al., 2001; Seamark et al., 2004). To provide the best care for this patient group the importance of an informed, knowledgeable multi-disciplinary team can be regarded as vital. A UK national survey into the roles and training of respiratory nurses in 389 general practices however found 52\% of COPD nurses with an advanced role had no accredited COPD training (Upton et al., 2007).

In the UK an educated workforce has been identified as a requisite for evidence based healthcare DH, 2000; DH, 2008). Focused to improve quality of patient care, these policies come against a backdrop of a cash-strapped National Health Service. The implication of this for providers of CPD is that to justify financial investment, appraisal of education by purchasers and commissioners may become more directly linked to efficacy (Fletcher, 2007).

Respiratory Education UK (REUK) works in partnership with Edge Hill University to provide accredited specialist respiratory courses nationally, basing its provision on a multidisciplinary model of teaching via blended learning approaches.

This present study aims to consider whether participation in, and completion of, an accredited, nationally delivered diploma level COPD module improves students' perceived knowledge and reported practice regarding diagnosis and management of COPD. The present study is part of an enquiry that utilised a mixed methods approach (Cresswell et al., 2003) measuring knowledge acquisition and explored links with clinical practice. A pre-test, post-test quasi-experimental design, incorporating the use of questionnaires, was used to gather data from an intervention and control group in both a quantitative and qualitative manner. The mixed methods approach chosen enabled corroboration of the educational intervention and demonstrated a tenable link with clinical practice. The focus of this paper is the findings of the qualitative element of this study.

\section{Literature review}

\section{Search strategy}

Databases searched: CINHAL; MEDLINE and ACADEMIC SEARCH ELITE Key terms: respiratory; education; specialist; academic; training. Using free text the key search terms were entered into each database respectively. The Boolean and was used to combine terms and focus the search. Papers retrieved were appraised for relevance and reference lists scrutinised to identify secondary references. Literature selected was limited to a 12-year period (1997-2009) to enable consideration of current education and health agendas. Literature in the final review was grouped under common themes of respiratory specialist education and clinical efficacy, and impact of specific respiratory education.

Overall there is a paucity of evidence concerning outcomes of respiratory education within the literature, and whilst the need for relevant knowledge is recognised (McIntyre, 2002; Rafferty and Elborn, 2004) there is little underpinning empirical or theoretical evidence cited. Nonetheless, studies have shown that specialist intervention can have a positive impact on patient outcomes (Madge et al., 1997; Griffiths et al., 2004), despite the elusive link with educational preparation,

\section{Respiratory specialist education and clinical efficacy}

Explicit research regarding these outcomes in COPD care is emerging and there is now evidence supporting nurse and multidisciplinary team (MDT) intervention with COPD patients as two reviews have detailed (Ram et al., 2004; Taylor et al., 2005). A consistent limitation of studies included in these reviews however is the lack of detail regarding education of the specialists delivering care. Despite this absent link with educational preparation studies have shown that specialist respiratory nurse intervention has a positive impact on the use of healthcare resources and patient outcomes (Madge et al., 1997; Griffiths et al., 2004; Foster et al., 2005).

It may seem a fundamental lapse that in all the evidence of efficacy of COPD care to date, the educational preparation of the 'specialists' involved in care delivery is seldom considered. In addition, the success of interventions, when demonstrated, is rarely attributed to the educational attainment of the healthcare team delivering the care.

\section{Impact of specific respiratory education}

Other literature does seek to expose a link between practice and educational preparation (Cleland et al., 2006; Hoskins et al., 1999) though selection biases skewed results a link, albeit indirect, between education and clinical outcomes is made. This link is further supported by Considine et al. (2005) when assessing the effect of a self-directed learning package on emergency nurses' knowledge of oxygen therapy. The researchers, through a pre-test/post-test, controlled, quasi-experimental design explored and attempted to link knowledge acquisition with clinical practice in emergency department nurses. Significant increases in post-test knowledge scores indicated efficacy of the intervention. Post-test analysis highlighted a negative correlation with pre-test score (i.e. the higher the pre-test score the less gain in knowledge; a ceiling effect) and a positive correlation with post-graduate qualifications highlighting the importance of prior knowledge and previous academic qualifications. This Australian study, although limited to nurses, undoubtedly adds to the evidence demonstrating that educational intervention increases knowledge.

The same researchers proceeded to study a smaller group of nurses $(N=20)$ to see if the intervention affected clinical decisions using parallel-form patient scenario interviews (Considine and Botti, 2006). The results showed an increase in knowledge, though the effect on clinical decision making was variable. A major limitation was interviewer bias and the use of hypothetical and simulated patient problems, restricting transferability into real-life practice. Nevertheless the researchers had recognised a need for evaluative methods from a clinical perspective, and condemning traditional evaluative measures - such as participant satisfaction - had sought to link knowledge with practice (Considine et al., 2007).

The most unequivocal evidence linking education to impact on clinical practice is found through a study examining whether allergy training was linked with outcomes for patients with mild perennial rhinitis (Sheikh et al., 2007). This experimental study demonstrated an improvement in the primary outcome of patients' quality of life in favour of a specifically trained health professional. The researchers also investigated the effects on professional competence and confidence and over three-quarters of participating healthcare professionals were of the opinion that they had acquired new knowledge and skills. Although subjective, these findings still make an important contribution to the scientific literature.

From a negative viewpoint the lack of respiratory training for health professionals has also been examined and linked to poor practice standards (Bolton et al., 2005). This survey exposed that poor and inconsistent training in relation to spirometry (one of the main diagnostic tools in respiratory care), suggesting that diagnosis of COPD is likely to be made on imprecise clinical grounds and supports a previous randomised controlled trial that demonstrated a positive training effect following spirometry workshops (Eaton et al., 1999).

It seems therefore whilst the research for effectiveness of various interventions to improve COPD and asthma care is evident, the 
educational preparation of the 'specialists' involved in care delivery is seldom considered. Nor is the success of such interventions, when demonstrated, attributed to the educational attainment of the healthcare team.

\section{Impact of non-respiratory but specific education}

The identification of the lack of empirical evidence supporting educational input and clinical outcomes is not limited to respiratory care (Tippett, 2004; Jordan et al., 1999; Edwards et al., 2007; Furze and Pearcey, 1999). Indeed this is an emergent field and it is apparent that researchers are now starting to recognise and address not only the elusive link between practice and education but also the appropriateness of various research methods for evaluating impact, including data collection instruments and the development of viable research designs and methods (Jordan, 2000; Griscti and Jacono, 2006; Davis and Galbraith, 2009). A recognition that it is often difficult to isolate the impact that education may have on the professional development of individuals has also been acknowledged within the literature (Ellis, 1996; Furze and Pearcey, 1999; Armstrong and Adam, 2002; Atkinson and Tawse, 2007; Rassool and Oyefeso, 2007; Shipman et al., 2008) and directs us to the complexities often associated with teaching and learning.

To summarise, whilst the research for effectiveness of various interventions in both COPD and asthma is evident, there is little empirical evidence to support the efficacy of educational preparation of clinicians to deliver these services. This reveals a gap in the literature and supports the need for endorsement of education.

\section{Research question}

What are the perceptions of participants of an accredited national COPD module regarding whether additional knowledge gained has impacted on their practice?

\section{Research design and methods}

The aim of education in clinical practice is to increase knowledge often with the assumption that this will improve patient outcomes. To support this notion of efficacy the perceived impact of the educational intervention on students' reported clinical practice was explored.

\section{Study design}

As part of a mixed methods study (Cresswell et al., 2003), qualitative data was gathered post-intervention through a semi-structured, self-completed questionnaire utilising openended questions to capture whether students perceived the module to have impacted upon their practice. The questionnaire was developed collaboratively with respiratory academics using a logical, systematic and structured approach (Rattray and Jones, 2007), resulting in three fundamental questions (Table 1). Construct and face validity were established through a small pilot group and endorsed by respiratory specialist colleagues.

\section{Data collection}

Qualitative data were collected through utilisation of a semistructured questionnaire. Demographics were recorded, including professional group, speciality, previous study, length of practice, and level of autonomy. The self-completed questionnaire was distributed in the classroom setting by the researcher; the voluntary nature of participation was addressed with an opt-out clause.

\section{Sample and intervention}

The sample itself was self-selected owing to the voluntary nature of participation in the module and the study. Data was collected from 68 students from convenience samples of seven cohorts from a variety of national locations delivered over a one year period (Table 2) following completion of the COPD module. The primary outcome was students' perceived knowledge and impact on practice as explored through the questionnaire, the intervention being a blended learning diploma level accredited COPD modular learning package. The blended delivery of this module is supported by comprehensive course materials (including course packs and e-learning modes) together with structured study days which facilitate classroom-based workshops, lectures and discussions. The module aims to provide healthcare workers with the knowledge and skills required to care for and manage patients with COPD from diagnosis, through the disease trajectory, to end of life care. Additionally, the philosophy of the module aims to confront attitudes, in particular nihilism and despondency, and challenge inconsistencies in practice, aiming to optimise and target practice in a way that reflects current scientific evidence and guidelines. The measurement of these aims was evident in the final questionnaire.

\section{Data analysis}

Responses to the three open-ended questions were analysed utilising themed content analysis. Investigator triangulation through subsequent data analysis by a fellow researcher aimed to increase internal validity and confirmability through verification of categories and themes (Cohen et al., 2005). An approach of giving quantitative measures to qualitative data, as used by Jinks and Chalder (2007), was then adopted to enable the utilisation of a quasi-statistical approach. This approach assesses the validity of the conclusions derived and ensures rogue responses do not set precedence (Seale and Silverman, 1997).

Table 2

Location of cohorts.

\begin{tabular}{ll}
\hline COHORT & Number of subjects $(n)$ \\
\hline Hull & 15 \\
Herts & 16 \\
Aintree 06 & 24 \\
Blackburn & 5 \\
North Wales & 9 \\
Aintree 07 & 21 \\
Belfast & 12 \\
Total & 102 \\
\hline
\end{tabular}

Table 1

The questions.

Has your personal practice towards COPD changed as a result of undertaking the course? If so what aspects?

Have any of your recommendations for practice in your clinical setting been implemented as a result of the course? If so please describe briefly.

Has your overall view of the management options for COPD changed? 


\section{Ethical considerations}

Ethical approval was sought and granted through the host University. Ethical issues were addressed through voluntary participation with an option to withdraw from the study at any time without prejudice.

\section{Results}

Data was gathered from 68 completed questionnaires. This represented $67 \%$ of the initial sample of 102 who commenced the module. The majority occupation was nursing (80.9\%). Other participating students were doctors (5.9\%), physiotherapists (10.3\%) and others (2.9\%) (Table 3 ).

All quotes were transcribed into word documents with an assigned questionnaire number and in order of the cohort group. These documents were then re-ordered into documents addressing specific questions which provided a platform for the content analysis whilst allowing traceability back to the original questionnaire and a particular (anonymous) student and cohort (Cohen et al., 2005). Some students gave more than one answer, for the purposes of data analysis these answers were separated into individual statements. Because of the high number of responses given, the frequency of answers within themes enabled exploration using quasi-statistical analysis (Jinks and Chalder, 2007) (Table 4). The incidence of answers that occur in each of the identified categories demonstrates the phenomenons identified are frequent, and therefore representative. The low frequency of rogue answers contributes to the overall reliability and internal validity of the questionnaire.

The three questions considered (Table 1) generated their own themes:

Q1 - confidence, awareness, knowledge and practice.

Q2 - change implementation, planning change and intention to change.

Table 3

Demographic data\% distribution.

\begin{tabular}{|c|c|c|}
\hline Subject & Variables & Sample (\%) \\
\hline \multicolumn{3}{|c|}{ Occupation } \\
\hline & Nurse & 80.9 \\
\hline & Doctor & 5.9 \\
\hline & Physiotherapist & 10.3 \\
\hline & Other & 2.9 \\
\hline \multicolumn{3}{|c|}{ Length of service } \\
\hline & $<5$ years & 16.2 \\
\hline & $5-10$ years & 25.0 \\
\hline & $10-20$ years & 41.2 \\
\hline & $>20$ years & 17.6 \\
\hline \multicolumn{3}{|c|}{ Specialist } \\
\hline & Specialist & 19.1 \\
\hline & Non-specialist & 80.9 \\
\hline \multicolumn{3}{|c|}{ Previous study } \\
\hline & Yes & 76.5 \\
\hline & No & 23.5 \\
\hline \multicolumn{3}{|c|}{ Level of study } \\
\hline & Short courses & 27.9 \\
\hline & Diploma & 44.1 \\
\hline & Degree & 4.4 \\
\hline & Post-graduate & 0 \\
\hline \multicolumn{3}{|c|}{ Autonomy in clinics } \\
\hline & Yes & 67.2 \\
\hline & No & 32.8 \\
\hline \multicolumn{3}{|c|}{ Nomination for study } \\
\hline & Self & 74.6 \\
\hline & Manager & 17.9 \\
\hline & Other & 7.5 \\
\hline
\end{tabular}

Table 4

Quasi-statistical analysis of the qualitative data.

\begin{tabular}{|c|c|c|c|}
\hline $\begin{array}{l}\text { Question number } \\
\text { (category) }\end{array}$ & Theme title & $\begin{array}{l}\text { Frequency } \\
\text { (number) }\end{array}$ & $\begin{array}{l}\text { Frequency } \\
(\%)\end{array}$ \\
\hline \multicolumn{4}{|l|}{ Q1 } \\
\hline & Confidence & 14 & 14 \\
\hline & Awareness & 26 & 26 \\
\hline & Knowledge & 21 & 21 \\
\hline & Practice specific & 39 & 39 \\
\hline & Outliers & 0 & - \\
\hline \multicolumn{4}{|l|}{ Q2 } \\
\hline & $\begin{array}{l}\text { Intention to } \\
\text { change }\end{array}$ & 9 & 17.3 \\
\hline & Planning change & 9 & 17.3 \\
\hline & $\begin{array}{l}\text { Change } \\
\text { implementation }\end{array}$ & 30 & 57.7 \\
\hline & Outliers & 4 & 7.7 \\
\hline \multicolumn{4}{|l|}{ Q3 } \\
\hline & Confidence & 17 & 21.3 \\
\hline & Awareness & 21 & 26.2 \\
\hline & Knowledge & 27 & 33.8 \\
\hline & $\begin{array}{l}\text { Personal } \\
\text { perception }\end{array}$ & 14 & 17.5 \\
\hline & Outliers & 1 & 1.2 \\
\hline
\end{tabular}

Q3 - confidence, awareness, knowledge and personal perception.

The incidence of answers that occur in each of the identified categories demonstrates the phenomenons identified are frequent, and therefore representative. A low occurrence of rogue answers contributes to the overall reliability and internal validity of the questionnaire.

\section{Question 1}

Overall the responses were positive, collectively demonstrating a change in personal practice as a result of undertaking the course.

\section{Confidence}

Fourteen (14\%) responses were coded as demonstrating an increase in confidence in affecting the care pathway, interacting with the multi-disciplinary team and consulting with patients themselves. In addition confidence was expressed in aspects such as spirometry, medications, assessing and diagnosing, making clinical decisions and enhancing clinical reasoning. One student's increase in confidence in personal practice was summarised as:

"In all aspects - I used to feel completely out of my depth but now feel I have the knowledge to start managing this disease".

\section{Awareness}

A raised awareness of issues in COPD care and management was demonstrated in 26 (26\%) of responses. These highlighted an insight into strategies such as pulmonary rehabilitation, oxygen therapy, anxiety and depression and end of life issues, including prognosis. As one student wrote: "( $\mathrm{I}$ am) more aware of psychological impact of disease and affects on patients."

Responses demonstrated an awareness of guidelines, multidisciplinary approaches to care and benefits available. An increased consciousness of patients' needs was expressed, "behavioural responses and how to tackle them" and a feeling of being more "empathetic".

\section{Knowledge}

Twenty-one (21\%) answers were deemed as an increase in knowledge, mainly specific learning points such as spirometry, 
oxygen therapy, arterial blood gas analysis, drug management, nutrition, diagnosis and differential diagnosis.

"(I have) more knowledge on spirometry and oxygen therapy."

\section{Practice specific}

Some answers were deemed to specify actual changes in clinical practice; this formed the majority domain with 39 (39\%) of answers. Examples of change included taking a more thorough history, interpretation of spirometry and making a correct diagnosis, and interpreting blood gases more competently.

By and large, personal practice was reported to have been influenced by the module, resulting in an increase in confidence and knowledge, a raised awareness and reported changes in clinical practice.

\section{Question 2}

Of 48 recorded answers to this question over half, 30 (57.7\%), reported an actual implementation of change (change implemented), with 9 (17.3\%) stating an intention to change an aspect of practice and 9 (17.3\%) indicated planning change.

\section{Change implemented}

Students reported that they now see more patients with COPD and are more involved in their care:

"Previously everybody just undertook spirometry - now a more detailed clinical and holistic approach is taken, concentrating on symptoms and history first."

Others reported purchase of equipment, namely spirometry and pulse oximeters; in addition the acquisition and distribution of patient education leaflets. The use of management plans, referral forms and written guidelines had been instigated. Regarding spirometry changes included screening:

"Yes - invite all over 45s smokers and ex-smokers to attend spirometry"

These reported changes demonstrate that students have developed not only knowledge but the ability to apply this to practice in an informed and evidence-based manner.

\section{Intention to change}

The code, 'intention to change' was applied to responses when it was uncertain that the change had occurred or processes put in place that would catalyst change. These included responses such as:

"(I) plan to conduct review process for all COPD patients and introduce patient education."

\section{Planning change}

For others implementation of change was being planned, this would mirror a usual time frame of change necessary following such educational input. Examples were: pulse oximeter was ordered, protocol being evaluated, lobbying for pulmonary rehabilitation services.

Overall participants recorded a variety of changes to clinical practice in various stages of implementation.

\section{Question 3}

This question generated 80 responses which were coded into themes of knowledge, confidence, awareness and personal perception of COPD.

\section{Confidence}

Seventeen $(21.3 \%)$ of the responses suggested an increase in confidence. For example nine respondents talked about an increase in confidence regarding discussions with patients about prognosis.

"(I'm) better equipped to handle questions and worries from patients."

Others discussed confidence in making accurate diagnosis and treatment. Another repeated claim was regarding their ability to "advise" and "reassure" and feeling "more confident discussing disease and prognosis with patients".

\section{Awareness}

The theme of awareness was used to code any answers that were deemed to give a broader account of altered views of management. Twenty-one answers (26.2\%) reported an increased awareness of services and management options open to their patients.

"(I'm) more aware of holistic help available for patients to improve QOL" (quality of life)

Others demonstrated an increased awareness of the potential benefits of some therapies to patients, for example pulmonary rehabilitation:

"(I was) surprised by the improvement in QOL that pulmonary rehabilitation can have."

\section{Knowledge}

Twenty-seven answers (33.8\%) reported an increase in knowledge; this was depicted through answers such as:

\section{"(I am) more aware of management for exacerbations".}

The fact that oxygen affects mortality in certain patients was a knowledge gain recognised by several students. Quite simply one student stated: "oxygen therapy prolongs life." Overall the use of oxygen therapy: when, how and why, was discussed specifically by 15 students (22\%). Some students stating quite specific points:

"(I) will not be as quick to administer oxygen if saturations less than 90."

\section{Personal Perceptions of COPD}

Fourteen (17.5\%) responses reported an altered personal perception of patients with COPD. Quotes such as: "more optimistic", "more sympathetic", "more holistic in approach", denoted a tendency to view the disease and its treatment differently. One student reported a "belief" in pulmonary rehabilitation, whilst another stated that they realised how much a patient's approach to illness affected outcomes, together with "a positive motivated frame of mind".

Traditionally many health care professionals may have viewed COPD nihilistically (van der Palen et al., 2004; Varkey, 2005). Whether this is as a result of the disease being perceived as self-inflicted or whether it's a response to the frustration of healthcare professionals regarding limitations in their knowledge and management options available is not clear. What is considered important however is that this stigma needs to be addressed in order to ensure that patients are treated optimally. As one student said:

“(I) don't feel as hopeless now, aware of more options for patients and when they would be appropriate."

Overall students reported changes in their general view of COPD and an altered personal perception of the disease and its management. 


\section{Discussion}

\section{Summary of findings}

The aim of the research was to examine the efficacy of a national accredited COPD module. The present paper addressed analysis of the post-intervention qualitative data to illustrate perceived impact upon clinical practice. The findings show that students perceived a gain in knowledge following completion of the course, illustrated with tangible reports of impacts upon clinical practice. Qualitative data prominently featured spirometry and diagnosis, with claims of increased knowledge, confidence and changes in practice. The apparent implications for this are that as a result of the intervention clinicians are able to obtain a more considered, accurate diagnosis and provide appropriate management targeted to the degree of disease severity. These findings would support economic benefits for the wider health and social care sectors.

Knowledge gains and reported practice changes concerning both acute and domiciliary oxygen is noteworthy. Appraisal of qualitative data inferred an overwhelming increase in confidence, awareness, knowledge and practice change related to oxygen therapy. Indeed the impact overall on practice regarding oxygen was reported in a multifaceted manner: purchase and use of oximetry, titration of oxygen to saturations, the need for assessment and follow-up, and the impact of oxygen on morbidity and mortality. By addressing this neglected area of practice inference of clinical impact seems patently justified.

The topic of pulmonary rehabilitation provided numerous examples of the reported impact on clinical practice regarding recognition of the evidence base supporting this intervention. Students reported an increased awareness of benefits, more likely to refer, lobbying for funding and generally promoting the concept to both patients and colleagues. The need to educate healthcare professionals regarding the evidence base for such interventions seems essential in today's cost-conscious climate.

Several students cited the way the course had changed their knowledge and attitudes towards COPD. The final open-ended question intended to probe holistic management through the exploration of students' personal perceptions of the disease. This generated numerous responses that illustrated a change in attitude as a result of undertaking the course. Although nihilism was not raised by any of the students as an issue, an inference can be made from the responses and reported changes in personal perceptions that would suggest a more positive, sympathetic and less condemning approach was now evident.

\section{Comparison with existing literature}

Previous authors (Tippett, 2004; Jordan et al., 1999; Edwards et al., 2007) have identified that acquisition of knowledge is not necessarily transferred to clinical practice and that there is a lack of research showing the impact of CPD on direct patient care (Furze and Pearcey, 1999; Jordan, 2000; Griscti and Jacono, 2006). This study has made an attempt to address this through reported changes in practice, although observational studies of direct patient care may be necessary to endorse these findings.

Within existing literature the evidence for the effectiveness of respiratory specialist intervention is evident (Madge et al., 1997; Griffiths et al., 2004; Cleland et al., 2006), however there was little support for the efficacy of educational preparation within these studies. This current study attempts to expose the link between education and clinical practice.

Other studies (Hoskins et al., 1999; Considine et al., 2005; Considine et al., 2007; Considine and Botti, 2006; Sheikh et al., 2007) have more overtly tried to support the connection between education of healthcare professionals and clinical effectiveness but have focused on very specific interventions rather than a patient group. The current study attempts to further augment this evidence in its suggestion that a wider curriculum may result in not only altered clinical practice but also wider issues such as awareness and personal perception.

In the respiratory field a lack of training has been linked with poor standards in both performing and interpreting spirometry (Bolton et al., 2005; Eaton et al., 1999). The findings of the current study support that educational input can influence knowledge of spirometry and increase application in practice through an increased level of confidence. Overall the current findings support the growing body of evidence denoting the links between education, knowledge and clinical outcomes.

Overall through analysis of the qualitative data, knowledge acquisition was verified; additionally, and perhaps more importantly, an impact on practice was reported. This finding suggests that when students gain knowledge they use it to the benefit of patients, and by equipping students with useful and practical knowledge, they can be empowered to initiate change and improve patient care directly. The current findings support the growing body of evidence denoting the links between education, knowledge and clinical outcomes.

\section{Limitations}

Limitations of this study need acknowledgment. In the sphere of studying the efficacy of education, the benefits of the richer information gleaned through the use of open-ended questions was particularly evident. Additionally the use of quantifying the content data provided a stronger position from which to derive meaning from the data. It is nevertheless recognised that the study is limited in a number of aspects. It was surmised that the outcome measures would not be affected by the relationship between the researcher and participants through anonymity and an option not to participate. Consideration nonetheless of the teacher/researcher's presence must be given and inherent biases within the data cannot be ruled out.

The convenience sample itself was by nature self-selected, and therefore external validity threatened (Polit et al., 2001). In addition the small sample size and 'specialist' nature of the educational intervention may negate more generalisable application of the findings.

The questionnaire as a data collection tool also had limitations. Content validity was checked through colleagues and face validity checked through a pilot group to identify issues such as clarity, readability and ease of administration, but the tool itself was not formally validated. The questionnaire may have limited the information collected from respondents, leading to a possible lack of sophistication and limited scope of the data collected (Cohen et al., 2005). Issues such as motivation, support (Spencer, 2006; Castles, 2004) together with constraints of funding (Dowsell et al., 1998) can radically influence the efficacy of an educational intervention.

Further research is clearly needed to verify the impact of clinical outcomes described upon patient management and financial resources (both spend and save). One method of measurement may be evaluation through observable performance outcomes, although this approach can be both time-consuming and labour-intensive. Qualitative data itself could have been richer, perhaps through the use of semi-structured interviews, further contextualising the reported benefits from students and identifying reasons for not implementing change (barriers or constraints); an area poorly addressed in the current study. Limited resources negated these approaches within the reported study.

Transferability of findings to other modules and methods of teaching and learning may be limited due to the specificity of the 
module content and the nature and expertise of the students. Nonetheless the findings do add support to the notion of knowledge acquisition and influence on clinical practice.

Finally, retention of knowledge should also be considered (Tippett, 2004) and often learning requires a period of consolidation, particularly before impacting upon practice; a longitudinal survey may address these aspects.

\section{Conclusions}

Whilst educational preparation is a strategy to ensure an educated and competent workforce, within a healthcare system facing escalating financial pressures it is becoming imperative for healthcare employers to justify allocation of budgets for training.

The study presented attempts not only to verify the nationally delivered COPD module but also to identify the elusive link that exists between knowledge acquisition and clinical practice. These findings suggest that when students gain knowledge they use it to the benefit of patients and can be empowered to initiate change and improve patient care directly.

\section{Conflict of interest statement}

Carol Kelly is employed full time by Edge Hill University, Lancashire with secondment to Respiratory Education UK three days per week. Respiratory Education UK is a registered charity in England at Unit 48, Ninth Avenue, University Hospital Aintree, Aintree, Liverpool L9 7AL. Charity Registration No: 1073428.

\section{Acknowledgements}

I wish to thank Dr. Dave Lynes with his help and support in undertaking this study and Professor Annette Jinks with her help in preparing the manuscript.

\section{References}

Armstrong, D.J., Adam, J., 2002. The impact of a postgraduate critical care course on nursing practice. Nurse Education in Practice 2, 169-175.

Atkinson, J., Tawse, S., 2007. Exploring haematology nurses' perceptions of specialist education's contribution to care delivery and the development of expertise. Nurse Education Today 27, 627-634.

Bolton, C.E., Ionescu, A.A., Edwards, P.H., Faulkner, T.A., Edwards, S.M., Shale, D.J., 2005. Attaining a correct diagnosis of COPD in general practice. Respiratory Medicine 99 (4), 493-500.

British Lung Foundation, 2007. Invisible Lives: COPD - Finding the Missing Millions. <www.lunguk.org> (accessed 14.07.09).

British Medical Association, 2003. New GMS Contract: Investing in General Practice. BMA, London.

Castles, J., 2004. Persistence and the adult learner. Active Learning in Higher Education 5 (2), 166-179.

Cleland, J., Mackenzie, M., Small, I., Douglas, G., Gentles, I., 2006. Developing COPD management in the community in North-East Scotland. Airways Journal 4 (2), 91-96.

Cohen, L., Manion, L., Morrison, K., 2005. Research Methods in Education, fifth ed. RoutlidgeFalmer, Oxon.

Considine, J., Botti, M., 2006. The effects of specific educational preparation on emergency nurses' clinical decisions regarding supplemental oxygen administration. Nursing and Health Sciences 8 (2), 73-80.

Considine, J., Botti, M., Thomas, S., 2005. Effect of a self-directed learning package on emergency nurses' knowledge of assessment of oxygenation and use of supplemental oxygen. Nursing and Health Sciences 7 (3), 199-208.

Considine, J., Botti, M., Thomas, S., 2007. The effect of education on hypothetical and actual oxygen administration. Nurse Education Today 27 (6), 651-660.

Cresswell, J.W., Plano Clark, V., Gutmann, M., Hanson, W., 2003. Advances in mixed methods design. In: Tashakkori, A., Teddlie, C. (Eds.), Handbook of Mixed Methods in the Social and Behavioural Sciences. Sage, Thousand Oakes, CA.

Davis, D., Galbraith, R., 2009. Continuing medical education effect on practice performance. Chest $135,42 \mathrm{~S}-48 \mathrm{~S}$.

Deapartment of Health, 2006. Our Health, Our Care, Our Say: A New Direction for Primary Care Services. HMSO, London.

Department of Health, 2000. The NHS Plan: A Plan for Investment, A Plan for Reform. HMSO, London.
Department of Health, 2008. High Quality Care for All: NHS Next Stage Review Final Report. HMSO, London.

Dowsell, T., Hewison, J., Hinds, M., 1998. Motivational forces affecting participation in post-registration degree courses and effects on home and work life: a qualitative study. Journal of Advanced Nursing 28 (6), 1326-1333.

Eaton, T., Withy, S., Garrett, J., Mercer, J., Whitlock, R., Rea, H., 1999. Spirometry in primary care practice: the importance of quality assurance and the impact of spirometry workshops. Chest 116 (2), 416-423.

Edwards, H., Walsh, A., Courtney, M., Monaghan, S., Wilson, J., Young, J., 2007. Improving paediatric nurses' knowledge and attitudes in childhood fever management. Journal of Advanced Nursing 57 (3), 257-269.

Ellis, L.B., 1996. Evaluating the effects of continuing nurse education on practice: researching for impact. Nursing Times Research 1 (4), 296-305.

Fletcher, M., 2007. Continuing education for healthcare professionals: time to prove its worth. Primary Care Respiratory Journal 16 (5), 188-190.

Foster, G., Gantley, M., Feder, G., Griffiths, C., 2005. How do clinical nurse specialists influence primary care management of asthma? A qualitative study. Primary Care Respiratory Journal 14, 154-160.

Furze, G., Pearcey, P., 1999. Continuing education in nursing: a review of the literature. Journal of Advanced Nursing 29 (2), 355-363.

Global Initiative for Chronic Obstructive Lung Disease (GOLD), 2009. Global Strategy for the Diagnosis, Management and Prevention of COPD. <www.goldcopd.com> (accessed 14.01.10).

Griffiths, C., Foster, G., Barnes, N., Eldridge, S., Tate, H., Begum, S., Wiggins, M., Dawson, C., Livingstone, A.E., Chambers, M., Coates, T., Harris, R., Feder, G.S., 2004 Specialist nurse intervention to reduce unscheduled asthma care in a deprived multiethnic area: the east London randomised controlled trial for high risk asthma (ELECTRA). British Medical Journal doi:10.1136/bmj.37950. 784444.EE.

Griscti, O., Jacono, J., 2006. Effectiveness of continuing education programmes in nursing: literature review. Journal of Advanced Nursing 55 (4), 449-456.

Guthrie, S.J., Hill, K.M., Muers, M.F., 2001. Living with severe COPD. Respiratory Medicine 95, 196-204.

Hogston, R., 1995. Nurses' perceptions of the impact of continuing professional education on the quality of nursing care. Journal of Advanced Nursing 22, 586-593.

Hoskins, G., Neville, R.G., Smith, B., Clark, R.A., 1999. The link between practice nurse training and asthma outcomes. British Journal of Community Nursing 4 (5), 222-228.

Jinks, A.M., Chalder, G., 2007. Consensus and diversity: an action research study designed to analyse the roles of a group of mental health consultant nurses. Journal of Clinical Nursing 16 (7), 1323-1332.

Jordan, S., 2000. Educational input and patient outcomes: exploring the gap. Journal of Advanced Nursing 31 (2), 461-471.

Jordan, S., Coleman, M., Hardy, B., Hughes, D., 1999. Assessing educational effectiveness: the impact of a specialist course on the delivery of care. Journal Advanced Nursing 30 (4), 796-807.

Madge, P., McColl, J., Paton, J., 1997. Impact of a nurse-led home management training programme in children admitted to hospital with acute asthma: a randomised controlled study. Thorax 52 (3), 223-228.

McIntyre, P., 2002. Breathing space. Nursing Standard 16 (28), 61.

Polit, D.F., Beck, C.T., Hungler, B.P., 2001. Essentials of Nursing Research: Methods, Appraisal and Utilisation, fifth ed. Lippincott, Philadelphia.

Rafferty, S., Elborn, S., 2004. The role of the respiratory nurse specialist. Clinical Pulmonary Medicine 11 (4), 228-236.

Ram, F.S.F., Wedzicha, J.A., Wright, J., Greenstone, M., 2004. Hospital at home for patients with acute exacerbations of COPD: a systematic review of evidence. British Medical Journal 329 (August), 315-318.

Rassool, G.H., Oyefeso, A., 2007. Predictors of course satisfaction and perceived course impact of addiction nurses undertaking a postgraduate diploma in addictive behaviour. Nurse Education Today 27, 256-265.

Rattray, J., Jones, M.C., 2007. Essential elements of questionnaire design and development. Journal of Clinical Nursing 16 (2), 234-243.

Seale, C., Silverman, D., 1997. Ensuring rigour in qualitative research. European Journal of Public Health 7, 379-384.

Seamark, D.A., Blake, S.D., Seamark, C.J., Halpin, D.M., 2004. Living with severe chronic obstructive pulmonary disease (COPD): perceptions of patients and their carers. An interpretive phenomenological analysis. Palliative Medicine 18 (7), 619-625.

Sheikh, A., Khan-Wasti, S., Price, D., Smeeth, L., Fletcher, M., Walker, S., 2007. Standardised training for healthcare professionals and its impact on patients with perennial rhinitis: a multi-centre randomised controlled trial. Clinical and Experimental Allergy 37 (1), 90-99.

Shipman, C., Burt, J., Ream, E., Beynon, T., Richardson, A., Addington-Hall, J., 2008. Improving district nurses' confidence and knowledge in the principles and practice of palliative care. Journal of Advanced Nursing 63 (5), 494-505.

Spencer, R.L., 2006. Nurses', midwives' and health visitors' perceptions of the impact of higher education on professional practice. Nurse Education Today 26, 45-53.

Taylor, S., Candy, B., Bryar, R., Ramsay, J., Vrijhoef, H., Esmond, G., Wedzicha, J., Griffiths, C., 2005. Effectiveness of innovations in nurse led chronic disease management for patients with COPD: systemic review of the evidence. British Medical Journal doi:10.1136/bmj.38512.664167.8F.

Tippett, J., 2004. Nurses' acquisition and retention of knowledge after trauma training. Accident and Emergency Nursing 12 (1), 39-46.

Upton, J., Madoc-Sutton, H., Sheikh, A., Frank, T.L., Walker, S., Fletcher, M., 2007. National survey on the roles and training of primary care respiratory nurses in 
the UK in 2006: are we making progress? Primary Care Respiratory Journal 16 (5), 284-290.

van der Palen, J., Monninkhof, E., van der Valk, P., Visser, A., 2004. Managing COPD: no more nihilism! Patient Education and Counselling 52 (3), 221223.
Varkey, B., 2005. Chronic obstructive pulmonary disease: from nihilism to tempered optimism. Current Opinion in Pulmonary Medicine 11 (2), 113-114.

Wildman, S., Weale, A., Clinton, R., Pritchard, J., 1999. The impact of higher education for post-registration nurses on their subsequent clinical practice: an exploration of students' views. Journal of Advanced Nursing 29 (1), 246-253. 